\title{
Extraction of a large mollusc shell impacted in the cervical esophagus: a twin-grasping approach could be the answer
}

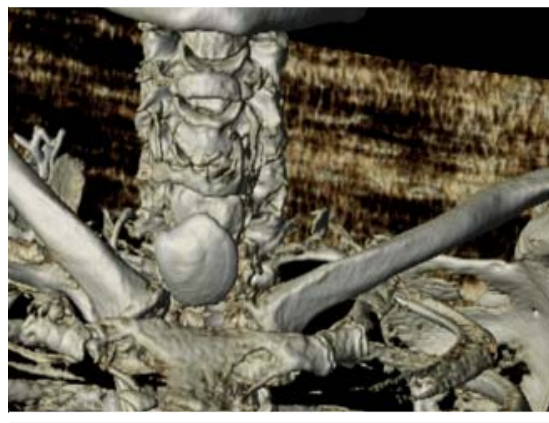

- Fig. 1 Radiological (computed tomography scan) findings before endoscopy. Three-dimensional reconstruction of the anatomical location of the foreign body and its relationship with adjacent structures.

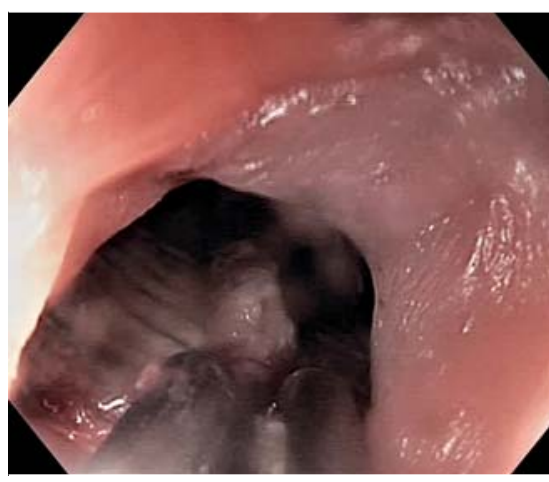

Fig. 2 Foreign body extraction with a double-channel gastroscope. Capture of the mollusc with the rat-tooth and alligator-tooth forceps.

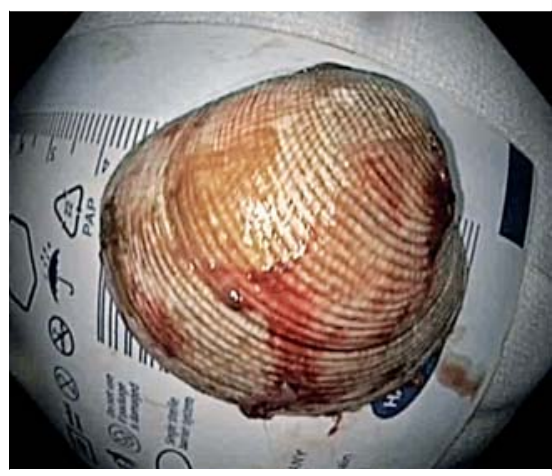

- Fig. 3 The extracted 36-mm mollusc shell.

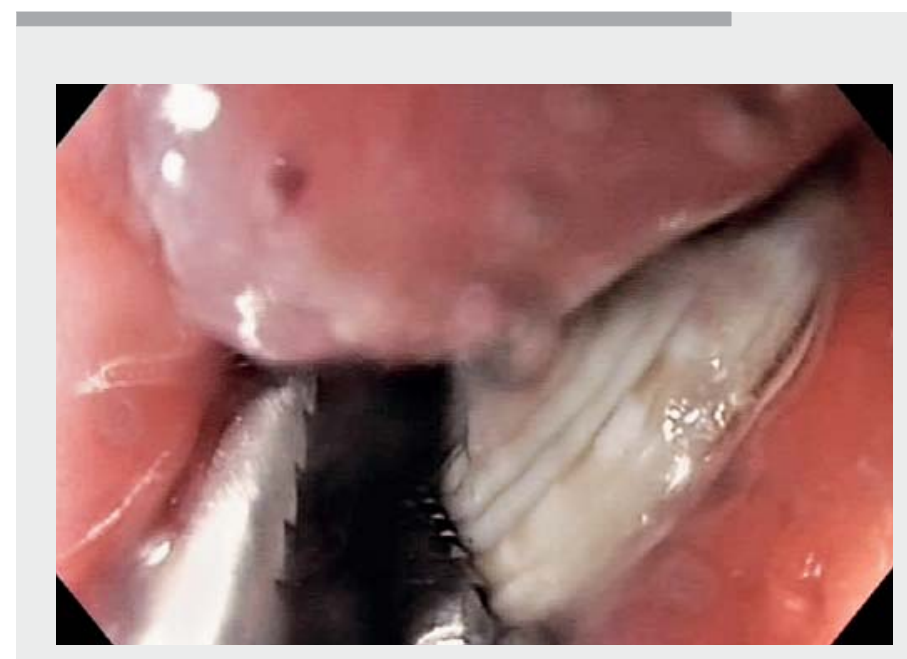

$\checkmark$ Video 1 Extraction of a large mollusc shell impacted in the cervical esophagus using twin grasping with two foreign body forceps.
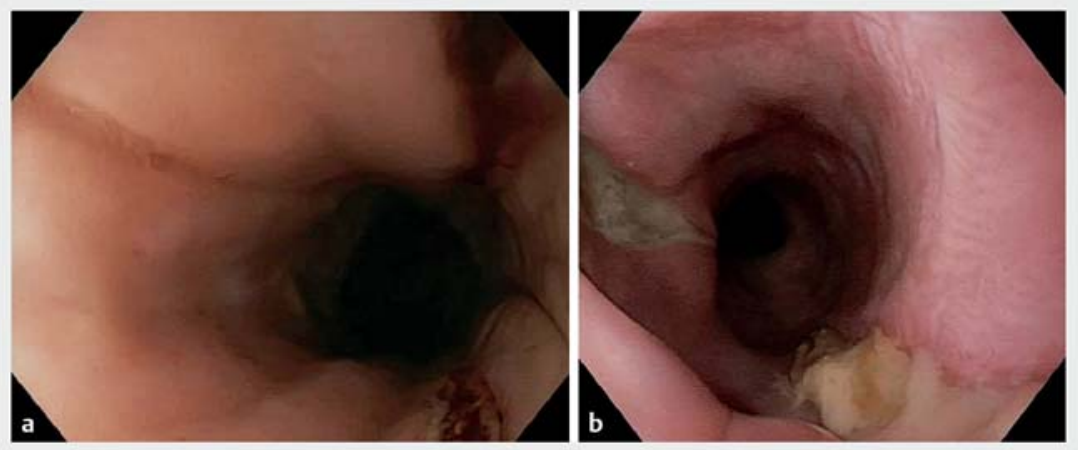

- Fig. 4 Endoscopic review. a Two mucosal tears in the cervical esophagus after shell extraction. b Cervical esophagus 3 days after extraction.

A 57-year-old man with a history of bipolar disorder presented to the emergency room with a 48-hour history of aphagia without dyspnea. A chest X-ray revealed a calcium-dense foreign body in the cervical esophagus. Given the long symptom duration, a chest computed tomography scan was performed, ruling out complications ( $\mathbf{F i g} \mathbf{1}$ ). In accordance with European Society of Gastrointestinal Endoscopy recommendations [1], we per- formed an emergency therapeutic endoscopy within 2 hours after admission. A large mollusc shell was observed tightly impacted in the upper esophagus ( $\downarrow$ Video 1). Endoscopic extraction with a conventional gastroscope and diverse forceps/devices was attempted without success, despite correct grasping, due to slippage against the anchored shell. A second endoscopy was performed the following morning. We decided to switch 
to a therapeutic double-channel gastroscope (Olympus Evis Exera II GIF2TH180; Olympus, Tokyo, Japan) and used two foreign body forceps (alligatorand rat-tooth forceps) simultaneously and in parallel, in an attempt to achieve a better grasping force (> Fig.2). After a few attempts with the two forceps, which were handled by two assistants performing continuous but low-power traction, a $36-\mathrm{mm}$ mollusc shell was extracted (> Fig.3). Endoscopic review following extraction showed two deep mucosal tears in the cervical esophagus ( Fig.4a). Given no local complication was identified, no further treatment was performed. In a follow-up endoscopy before discharge, mucosal healing without stenosis was confirmed ( $\triangleright$ Fig. $\mathbf{4 b}$ ).

Foreign body ingestion and food bolus impaction are commonly encountered in clinical practice, and approximately $10 \%-20 \%$ of cases require endoscopic removal [1]. Working with two parallel foreign body forceps on the same axis as the gastroscope allows a more consistent and better distributed traction force in the correct direction over two points, which also prevents slippage [2,3].

Endoscopy_UCTN_Code_TTT_1AO_2AL

\section{Competing interests}

The authors declare that they have no conflict of interest.
The authors

Oscar Nogales $₫$, Celia Caravaca Gámez, Jon de la Maza, Julia del Río Izquierdo, Javier García-Lledó, Isabel Payeras, Beatriz Merino Rodríguez

Department of Digestive Diseases, Endoscopy Unit, Hospital General Universitario Gregorio

Marañón, Madrid, Spain

Corresponding author

\section{Oscar Nogales, MD}

Department of Digestive Diseases, Endoscopy Unit, Hospital General Universitario Gregorio Marañón, Calle Doctor Esquerdo 46, 28007 Madrid, Spain oscarnogalesrincon@gmail.com

\section{References}

[1] Birk M, Bauerfeind P, Deprez PH et al. Removal of foreign bodies in the upper gastrointestinal tract in adults: European Society of Gastrointestinal Endoscopy (ESGE) Clinical Guideline. Endoscopy 2016; 48: 489-496

[2] Galloro G, Sivero L, Magno L et al. New technique for endoscopic removal of intragastric balloon placed for treatment of morbid obesity. Obes Surg 2007; 17: 658-662

[3] Beldholm BR, Lee AU. Simple endoscopic technique for retrieving a long foreign body from the stomach. ANZ J Surg 2007; 77 : 560-561
Bibliography

Endoscopy 2022; 54: E445-E446

DOI 10.1055/a-1625-3337

ISSN 0013-726X

published online 17.9.2021

(c) 2021. Thieme. All rights reserved.

Georg Thieme Verlag KG, Rüdigerstraße 14,

70469 Stuttgart, Germany

\section{ENDOSCOPY E-VIDEOS}

https://eref.thieme.de/e-videos

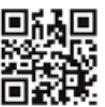

Endoscopy E-Videos is an open access online section, reporting on interesting cases and new techniques in gastroenterological endoscopy. All papers include a high quality video and all contributions are freely accessible online. Processing charges apply (currently EUR 375), discounts and wavers acc. to HINARI are available.

This section has its own submission website at https://mc.manuscriptcentral.com/e-videos 